\title{
Motion - Colonoscopic surveillance is more cost effective than colectomy in patients with ulcerative colitis: Arguments for the motion
}

\author{
Bret A Lashner MD
}

\begin{abstract}
BA Lashner. Motion - Colonoscopic surveillance is more cost effective than colectomy in patients with ulcerative colitis: A rguments for the motion. Can J G astroenterol 2003;17(2):119-121.

Patients with ulcerative colitis (U C) are at increased risk for colorectal cancer (CRC), especially those with longstanding disease, pancolitis or primary sclerosing cholangitis. The incidence of colitisassociated cancer is increasing, and the mortality rates from C RC are higher in U C patients than in the general population. C ase control studies have demonstrated that surveillance colonoscopy reduces the risk of dying from CRC. A well conducted decision analysis found that surveillance colonoscopy decreases cancer-related mortality and increases life expectancy. The results with surveillance programs were almost as good as with prophylactic colectomy. A subsequent cost effectiveness analysis using the same model found that, compared with a policy of no surveillance, colonoscopic surveillance was more effective at preventing death from CRC and was less costly. The best strategy appears to be to perform col on oscopies every three years. The analysis also showed that colectomy should be recommended in patients with low-grade dysplasia. Patients at very high risk for CRC should undergo yearly colonoscopy, and patients who are concerned about the limitations of this technique should be offered prophylactic colectomy.
\end{abstract}

Key Words: Cancer surveillance; Colorectal cancer; U Icerative colitis

$P$ rotocols for the detection of neoplastic lesions by surveillance colonoscopy have evolved over the past 30 years, and have become the standard of care in high risk patients with ulcerative colitis (UC). Throughout the world, colonoscopy is routinely undertaken to detect dysplasia and asymptomatic cancers. Efforts to minimize the cost of this expensive form of cancer surveillance would allow it to be offered to as many patients as possible within the financial constraints of the health care system.

\section{COLORECTAL CANCER IN UC}

Recent studies from Sweden, D enmark, G reece, G ermany and Japan have found that the cumulative incidence of colorectal cancer (CRC) in UC patients is between $5 \%$ and $13 \%$ (1-5). $W$ hile these figures are not very different from the $C R C$ risk in the general population, the younger age at onset of cancer in

\section{M otion - La surveillance par coloscopie est plus rentable que la colectomie chez les patients atteints de rectocolite hémorragique : arguments en faveur de la motion}

RÉSU MÉ : Les patients atteints de rectocolite hémorragique $(\mathrm{RCH})$, notamment ceux qui souffrent de la maladie depuis longtemps, de pancolite ou de cholangite sclérosante primitive, sont prédisposés au cancer colorectal (CCR). L'incidence du cancer associé à la colite augmente, et les taux de mortalité attribuables au CCR sont plus élevés chez les patients atteints de RCH que dans la population en général. Les études cas/témoins ont montré que la coloscopie de contrôle réduisait les risques de succomber à un CCR. Selon une analyse décisionnelle bien conçue, la coloscopie de contrôle diminue la mortalité liée au cancer et augmente I'espérance de vie. Les résultats de programmes de surveillance se sont montrés presque aussi bons que ceux de la colectomie prophylactique. U ne analyse ultérieure de rentabilité réalisée à l'aide du même modèle a montré que la surveillance par coloscopie s'avérait plus efficace que la non-surveillance pour prévenir la mort due à un CCR tout en étant moins coûteuse. La fréquence optimale consisterait en la pratique de coloscopies tous les trois ans. L'analyse a également révélé que la colectomie devrait être recommandée dans les cas de dysplasie de faible degré de malignité. Les patients fortement prédisposés au C CR devraient subir une coloscopie annuelle, et la colectomie prophylactique devrait être proposée aux patients qui se montrent inquiets des limites de la technique.

U C patients means that the age specific relative risk is greater than three.

A s with sporadic CRC, cancer-related mortality in UC patients with CRC is approximately $50 \%$. Some investigators, however, have reported that the mortality rates from rectal cancer in UC patients are greater than in sporadic rectal cancer $(6,7)$. O $\mathrm{n}$ the other hand, while incidence rates for CRC in patients with UC have been rising, mortality rates from this tumour have been decreasing (8). The divergence of incidence and mortality curves suggests that UC patients are enjoying longer life expectancies, which is likely related to improvements in treatment and cancer surveillance.

Patients with longstanding and anatomically extensive disease are especially likely to develop CRC. There is also evidence that a young age at disease onset is an independent risk factor (9). Primary sclerosing cholangitis (PSC) has recently

This article was originally presented at a symposium entitled, "C ontroversies in G astroenterology", sponsored by A xcan Pharma, Toronto, 0 ntario, A pril 8 to 10, 2002

C enter for Inflammatory B owel D isease, C leveland C linic Foundation, C leveland, O hio, U SA

C orrespondence: D r BA Lashner, C enter for Inflammatory B owel D isease, Cleveland C linic Foundation, 9500 E uclid A venue, 1A 30, C leveland,

0 hio 44195, U SA. Telephone 216-444-6524, fax 216-444-6305, e-mail lashneb@ccf.org 
TABLE 1

Costs of surveillance strategies

\begin{tabular}{lcccc}
\hline Strategy & $\begin{array}{c}\text { Number of } \\
\text { colonoscopies } \\
\text { per patient }\end{array}$ & $\begin{array}{c}\text { Percentage } \\
\text { undergoing elective } \\
\text { surgery }\end{array}$ & $\begin{array}{c}\text { Percentage } \\
\text { undergoing urgent } \\
\text { surgery }\end{array}$ & $\begin{array}{c}\text { Percentage } \\
\text { of remaining life } \\
\text { expectancy after surgery }\end{array}$ \\
\hline No surveillance & 2.69 & 55 & 16.7 & 44 \\
Surveillance & 5.14 & 84 & 8.9 & 73 \\
Prophylactic colectomy & 0 & 100 & 0 & 100 \\
\hline
\end{tabular}

Data from Provencale et al (14)

been identified as an additional risk factor. The small proportion of UC patients with PSC (approximately $2 \%$ ) has a relative risk for $C R C$ of at least three, compared with U C patients without PSC (10). Patients with PSC should, therefore, be made aware of the magnitude of this risk and undergo either frequent surveillance colonoscopies or prophylactic colectomy. 0 ne study has shown that the incidence of dysplasia and cancer can be reduced by treatment with ursodeoxycholic acid, which alters bile salt composition in PSC patients (11). Chemoprevention is not a substitute for cancer surveillance, however.

\section{EFFECTIVENESS OF CAN CER SU RVEILLAN CE}

Surveillance colonoscopy reduces the cancer-rel ated mortality in patients with UC, as has been shown in two case control studies $(12,13)$. M oreover, increased frequency of surveillance is associated with a larger reduction in mortality.

The strongest evidence for the effectiveness of cancer surveillance comes from a decision analysis. In this study, Provenzale et al (14) applied the best available data to a hypothetical cohort of 30-year-old patients with a 10-year history of ulcerative pancolitis without PSC. They compared 17 different cancer surveillance strategies with either prophylactic colectomy or no surveillance (ie, colectomy only when symptomatic cancer is detected). The estimated cumulative incidence of cancer in the 'no surveillance' group was $6.67 \%$. The strategy of performing surveillance colonoscopy every three years, and colectomy for patients with even low grade dysplasia, resulted in a decrease in cumulative cancer incidence to $0.47 \%$. Of course, prophylactic colectomy eliminated the risk of CRC. The remaining life expectancy in the cohort was 46.31 years with no surveillance, 47.19 years with surveillance every three years, and 47.45 years with prophylactic colectomy. The authors concluded that the cancer risk and life expectancy could be dramatically improved by colonoscopic surveillance, and that the results were almost as good as with prophylactic colectomy.

\section{COST S OF CAN CER SU RVEILLAN CE}

The ben efits of cancer surveillance and prophylactic colectomy must be weighed against its costs, including increased frequencies of colonoscopy and surgery (both elective and urgent) and reduced quality of life following colectomy. Table 1 shows data from the decision analysis undertaken by Provenzale et al (14). It is apparent that both 'surveillance' and 'prophylactic colectomy' strategies are both more effective and more costly than 'no surveillance'.

\section{COST EFFECTIVENESS OF CANCER SU RVEILLAN CE}

Provenzale et al (15) later calculated cost effectiveness ratios from their model. They found that all surveillance strategies had lower costs and superior effectiveness than no surveillance. Therefore, a 'no surveillance' policy is unacceptable. $M$ oreover, strategies using low grade dysplasia as a criterion for performing a colectomy were both more effective and less costly than were those that used high grade dysplasia. The incremental cost effectiveness ratios for various colonoscopic surveillance strategies are listed in Table 2.

These ratios compare favourably to those derived from widely accepted surveillance regimens, such as mammography for breast cancer and Papanicolaou smears for cervical cancer. Specifically, colonoscopic surveillance every three years or at a variable interval, as defined in Table 2, are worthwhile. This means that the decrease in cancer risk and increase in life expectancy justify the costs of testing and surgery and the decreases in quality of life that follow colectomy.

A nother decision analysis has recently been published (16). It considered the costs of testing, surgery and terminal care for patients dying from $C R C$, as well as the number of life-years saved. The authors found that a strategy of colonoscopy every two years would become cost effective if the cumulative risk of developing CRC were $27 \%$. The threshold CRC risk was $19 \%$ for testing every three years, and $14 \%$ for testing every four years. In this model, surveillance was not cost effective compared with no surveillance. The poor effectiveness of the 'no surveillance' strategy, however, makes this option unacceptable. $N$ either of these two cost effectiveness analyses $(15,16)$ explored the option of prophylactic colectomy.

\section{IMPROVING COST EFFECTIVENESS}

Cancer surveillance colonoscopy regimens are cost effective compared with no surveillance, and are generally regarded as the standard of care for eligible patients. It is, therefore, incumbent on gastroenterologists to recommend surveillance, with parameters that maximize life expectancy at a reasonable cost.

Clinicians should pay close attention to patient selection, the criteria for recommending colectomy and the testing interval. Cost effectiveness ratios could be reduced by limiting surveillance to high risk patients, such as $U C$ patients who are at high risk for $C R C$, have pancolitis of at least seven years' duration or PSC. Because patients with left-sided U C, short duration of disease or C rohn's colitis are less likely to develop C RC, surveillance is associated with higher cost effectiveness ratios. Performing colectomy in patients with low grade dysplasia, as 
TABLE 2

Incremental cost effectiveness ratios for various surveillance strategies

\begin{tabular}{lc}
\hline Surveillance strategy & $\begin{array}{c}\text { Incremental cost effectiveness ratio } \\
\text { (per life-year gained) }\end{array}$ \\
\hline Every year versus every two years & $\$ 247,200$ \\
Every year versus variable interval $^{*}$ & $\$ 159,500$ \\
Variable interval $^{*}$ versus every three years & $\$ 155,400$ \\
Every three years versus every four years $^{\text {Every four years versus every five years }}$ & $\$ 111,600$ \\
Every five years versus no surveillance & $\$ 83,700$ \\
\hline
\end{tabular}

Data from Provenzale et al (15). *Colonoscopy every three years for the first 20 years of disease, every two years for the next eight years, and annually thereafter

opposed to high grade dysplasia, results in a higher cost (increased number of colectomies) but a disproportionately higher effectiveness (increased number of life-years saved), and thus a lower cost effectiveness ratio. A s al ready stated, the marginal cost effectiveness ratios are reasonable when

\section{REFEREN CES}

1. Karlén $P$, Löfberg R, Broström O, Leijonmarck CE, H ellers $G$, Persson PG . Increased risk of cancer in ulcerative colitis: A population-based cohort study. A m J G astroenterol 1999;94:1047-52.

2. Wandall EP, Damkier $P, M$ oller Pedersen $F$, W ilson $B$, Schaffalitzky de M uckadell OB. Survival and incidence of colorectal cancer in patients with ulcerative colitis in Funen county diagnosed between 1973 and 1993. Scand J G astroenterol 2000;35:312-7.

3. Triantafillidis JK, Emmanouilidis A, M anousos $0 \mathrm{~N}$, et al. $U$ Icerative colitis in G reece: Clinicoepidemiological data, course, and prognostic factors in 413 consecutive patients. J Clin Gastroenterol 1998;27:204-10.

4. Pohl C, H ombach A, Kruis W. Chronic inflammatory bowel disease and cancer. H epato-G astroenterology 2000;47:57-70.

5. Ishibashi N, H irota Y, I keda M, H irohata T. U Icerative colitis and colorectal cancer: A follow-up study in Fukuoka, Japan. Int J Epidemiol 1999;28:609-13.

6. Palli D, Trallori G, Saieva C, et al. General and cancer specific mortality of a population based cohort of patients with inflammatory bowel disease: the Florence Study. G ut 1998;42:175-9.

7. Bansal P, Sonnenberg A. Risk factors of colorectal cancer in inflammatory bowel disease. A m J G astroenterol 1996;91:44-8

8. Delcò F, Sonnenberg A. Birth-cohort phenomenon in the time trends of mortality from ulcerative colitis. A m J Epidemiol 1999:150:359-66

9. Langholz E, M unkholm P, Krasilnikoff PA, Binder V. Inflammatory bowel diseases with onset in childhood. Clinical features, morbidity, colonoscopy is performed every three years, or when the testing interval is adjusted according to the patient's individual risk (17). A nnual testing is not cost effective for patients with moderately high risk, nor is it an efficient use of scarce resources, but is appropriate for patients who are at very high risk for CRC, such as those with either PC S or extensive disease for more than 30 years.

\section{SU RVEILLAN CE VERSUS PROPH YLACTIC COLECTOMY}

A perfectly effective cancer surveillance colonoscopy program does not exist. For a variety of reasons, some patients develop cancer even though dysplasia was not detected at earlier colonoscopy. Patients who are concerned about the risk of cancer and cannot accept the limitations of cancer surveillance should undergo prophylactic colectomy. The ability to eliminate the risk of cancer should be weighed against the decrease in quality of life after colectomy. This personal decision is not necessarily based on cost effectiveness cal culations.

and mortality in a regional cohort. Scand J G astroenterol 1997;32:139-47.

10. Shetty K, Rybicki L, Brzezinski A, C arey W D, Lashner BA . The risk for cancer or dysplasia in ulcerative colitis patients with primary sclerosing cholangitis. A m J G astroenterol 1999;94:1643-9.

11. Tung BY, Emond MJ, H aggitt RC, et al. U rsodiol use is associated with lower prevalence of colonic neoplasia in patients with ulcerative colitis and primary sclerosing cholangitis. A nn Intern M ed 2001;134:89-95.

12. Eaden J, A brams K, Ekbom A, Jackson E, M ayberry J. Colorectal cancer prevention in ulcerative colitis: A case-control study. A liment Pharmacol Ther 2000;14:145-53.

13. Karlén $P$, Kornfeld $D$, Broström $O$, Löfberg $R$, Persson PG, Ekbom A . Is colonoscopic surveillance reducing colorectal cancer mortality in ulcerative colitis? A population based case control study. G ut 1998;42:711-4.

14. Provenzale D, Kowdley KV, A rora S, W ong JB. Prophylactic colectomy or surveillance for chronic ulcerative colitis? A decision analysis. G astroenterology 1995;109:1188-96.

15. Provenzale $D$, W ong JB, O nken JE, Lipscomb J. Performing a costeffectiveness analysis: Surveillance of patients with ulcerative colitis. A m J Gastroenterol 1998;93:872-80.

16. Delcò F, Sonnenberg A. A decision analysis of surveillance for colorectal cancer in ulcerative colitis. G ut 2000;46:500-6.

17. Lashner BA, H anauer SB, Silverstein M D. O ptimal timing of colonoscopy to screen for cancer in ulcerative colitis. A nn Intern M ed 1988;108:274-8. 


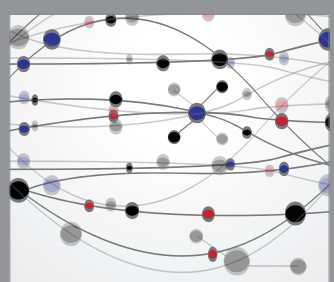

The Scientific World Journal
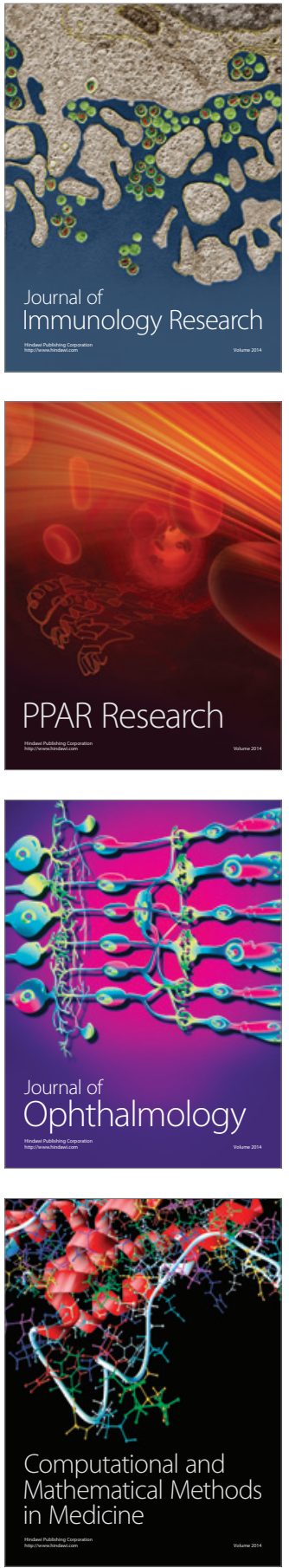

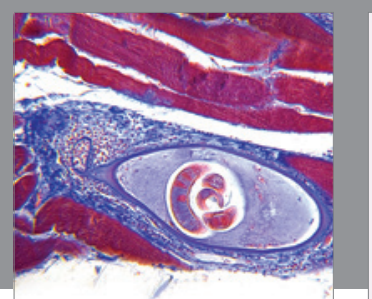

Gastroenterology Research and Practice

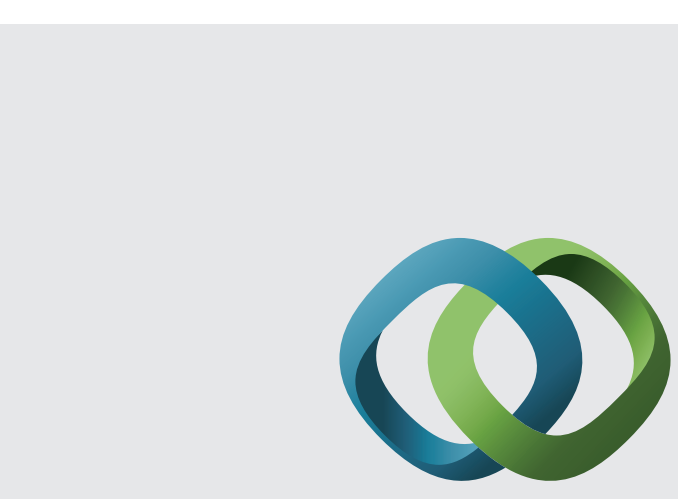

\section{Hindawi}

Submit your manuscripts at

http://www.hindawi.com
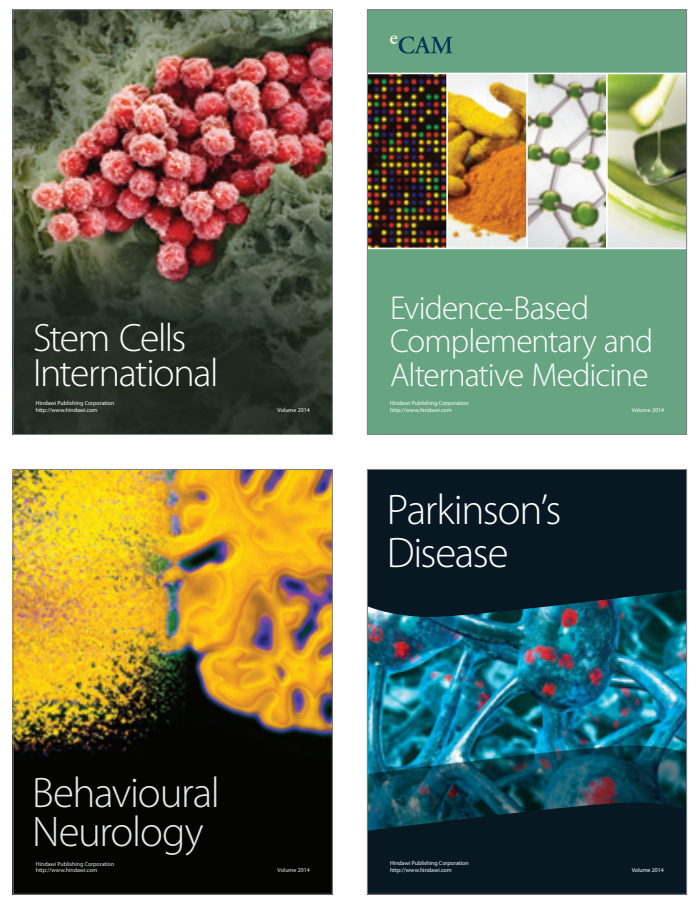
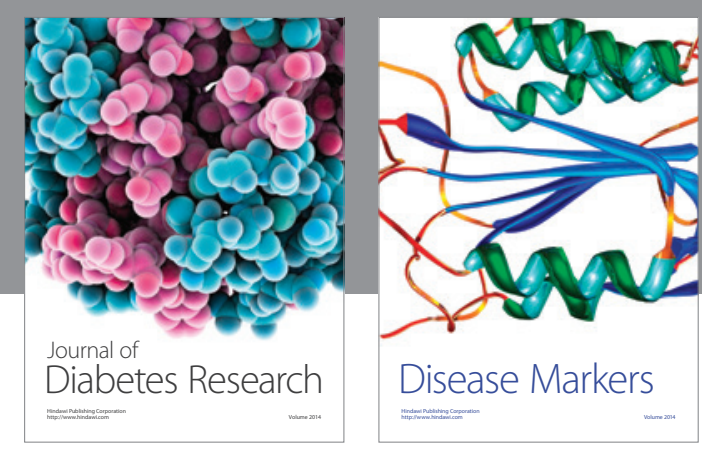

Disease Markers
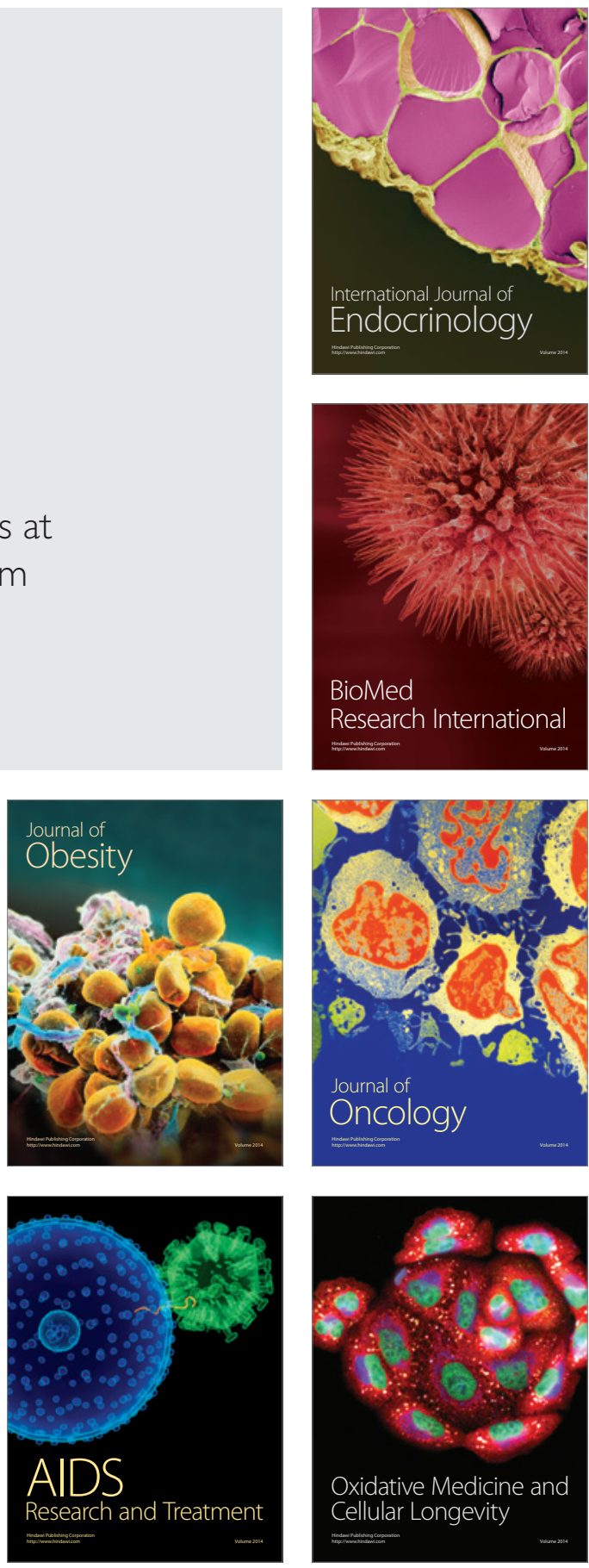